\title{
Female adolescents and the future of female genital mutilation/cutting: a report from an endemic area
}

\author{
Grace G Ezeoke, Abiodun S Adeniran, Kikelomo T Adesina, Adegboyega A Fawole, \\ Munirdeen A Ijaiya, Adebunmi O Olarinoye
}

Department of Obstetrics \& Gynecology, University of Ilorin/ University of Ilorin Teaching Hospital, Ilorin, Kwara State, Nigeria.

\section{Emails:}

Grace G. Ezeoke ; Tel: +234 8033823206; E-mail: graceaustin2004@yahoo.com; Abiodun S. Adeniran; Tel: +234 8057534788; E-mail: adeniran.as@unilorin.edu.ng; Kikelomo T. Adesina; Tel: +234 8033813442; E-mail: teminikike@yahoo.com; Adegboyega A. Fawole ; Tel: +234 8033586950; E-mail: faafaa2005@yahoo.com; Munirdeen A. Ijaiya; Tel: +234 8033801565; E-mail: munirdeenijaiya@yahoo.com; Adebunmi O. Olarinoye; Tel: +234 8033975764; E-mail: adebunmiolarinoye@yahoo.com

\begin{abstract}
Background: Despite collaborative efforts aimed at its eradication, Female Genital Mutilation/Cutting (FGM/C) continues in endemic areas.

Objective: To evaluate the experience and preparedness of female adolescents to protect their future daughters from FG$\mathrm{M} / \mathrm{C}$.

Methods: A cross-sectional survey involving adolescent secondary school girls in North Central Nigeria. Participants were secondary school students who completed the study's self-administered questionnaire after informed parental or participant's consent. Data management was with SPSS 20.0 (IBM, USA), P-value $<0.05$ was significant.

Results: There were 2000 participants aged $13-19$ years (mean 15.56 \pm 1.75 ), prevalence of FGM/C was 35.0\%, awareness was $86.1 \%$, mutilation was performed between infancy and eight years of age (mean 3.85 \pm 3.24 years), 644(32.2\%) desire to mutilatetheir future daughters, 722(36.1\%) expressed support for FGM/C and $63.1 \%$ of victims of FM/C reported adverse post-mutilation experiences. Support for FGM/C was associated with low social class (P0.0010), opinion that FGM/C has benefit (P0.001) and desire to mutilate future daughters (P0.001) while awareness of efforts to eradicate FMG/C was $813(40.7 \%)$.

Conclusion: FGM/C remains prevalent with potential support for its continuation among female adolescents despite reported adverse post-mutilation experiences. The multi-pronged approach to eradicate FGM/C should prioritize re-orientation for adolescent girls, rehabilitation of mutilated girls and girl child formal education.

Keywords: Female genital mutilation/cutting; female circumcision, harmful traditional practices, adverse childhood experiences.

DOI: https://dx.doi.org/10.4314/abs.v21i4.38

Cite as: Ezeoke GG, Adeniran AS, Adesina KT, Fawole AA, Ijaiya MA, Olarinoye AO. Female adolescents and the future of female genital mutilation/cutting: a report from an endemic area. Afri Health Sci. 2021;21(4):1808-16. https://dx.doi. org/10.4314/abs.v21it.38
\end{abstract}

\section{Corresponding author: \\ Abiodun Adeniran, \\ Department of Obstetrics \& Gynaecology, University of Ilorin, PMB 1515, Ilorin, Kwara State, Nigeria. \\ Tel: +23480 57534788 \\ E-mail: adeniran.as@unilorin.edu.ng}

\section{Introduction}

Female Genital Mutilation/ Cutting (FGM/C) is the removal of part or whole of the female external genitalia for non-medical reasons. ${ }^{1,2}$ It is an act of violence perhaps unintended against females with cultural and social coloration making it a mark of social integration in some communities. ${ }^{1}$ It was reported that over $66 \%$ of $\mathrm{FGM} / \mathrm{C}$ occur in four countries i.e. Ethiopia (22\%), 
Egypt (22\%), Sudan (11\%) and Nigeria (11\%)2 despite regional, national and inter-national collaboration towards its eradication. Global statistics showed that the prevalence decreased between 2005 and 2010 at a 1\% per year rate which if sustained will produce a $50 \%$ reduction by 2074 . However, this appears inadequate; thus, an accelerated reduction has been suggested for efforts to ensure a $50 \%$ reduction by 2030 at an annual reduction rate of $3.2 \%{ }^{2}$ although additional births will increase the number of vulnerable females during the same period. It was therefore projected that with the current prevalence, by 2030 about 20.7 million girls aged 15-19 born between 2010 to 2015 may have been mutilated representing an additional increase. This is projected to represent an increase from 4.5million in 2010 to 7.8 million by 2030 in West and Central Africa alone ${ }^{2}$ although the future risk for FGM/C varies depending on where the girl will live.

According to the report of the Multiple Indicator Cluster Survey (MICS) for 2016-17 by the National Bureau of Statistics in Nigeria, ${ }^{3} 18.4 \%$ of women aged 15 49 years had been mutilated, $61.8 \%$ were type I while the south-west had the highest regional prevalence of $41.1 \%$. Among daughters aged $0-14$ years, the national prevalence was $25.3 \%$, the highest regional prevalence was in the North-west $(56.0 \%)$ while $76.6 \%$ of the victims had type I mutilation. Awareness about FGM/C was $52.1 \%$ for women aged $15-49$ years, $21.6 \%$ favoured its continuation while $76.5 \%$ supported its eradication. ${ }^{3}$

Efforts aimed at eradicating FGM/C include advocacy, educational activities to correct myths, emphasis on the possible medical complications as well as stimulation of dialogue among households, community groups, traditional, religious and political leaders. Older women who quite often encouraged FGM/C as well as men who are major decision makers in most endemic areas have been recruited into the fight against FGM/C while alternative sources of income were explored for the local circumcisers. ${ }^{4}$ Public figures and opinion leaders have accepted and functions as 'champions' to encourage others to discontinue the act, the need to empower and respect the rights of girls and women has taken centre stage while alternative harmless cultural rituals were introduced to replace FGM/C in some communities. A number of countries have passed laws to punish those involved in FGM/C while immigration laws in non-endemic countries have been broadened to accommodate asylum for those persecuted for FGM/C.,2,4
It has been observed that while awareness about FG$\mathrm{M} / \mathrm{C}$ continues to increase, this has not produced a commensurate behaviour change. Researchers have attempted the use of theoretical models of behaviour change to understand the impact of interventions to stop FGM/C on knowledge, beliefs, attitudes and behaviours of the people. ${ }^{5}$ For social and health issues, cognitive models have been developed to analyzeehaviour change for a variety of problems; these include health belief model, theory of planned behaviour and theory of reasoned action although diffusion theory and trans-theoretical model are the commonly applied. ${ }^{6}$ The diffusion theory focuses on the process by which an innovation is communicated through certain channels over time among members of a social system. ${ }^{7}$ The model recognizes that an individual or decision-making group undergoes a process as decision about innovation is not an instantaneous act; but a process that passes through the stages of knowledge, persuasion, decision, implementation and confirmation. ${ }^{7}$ The trans-theoretical or stage of change model focuses on integrating behaviour change theories used in psychology (especially for smoking cessation); the stages include pre-contemplation, contemplation, preparation, action, maintenance as well as termination. ${ }^{8}$ The theory has been extended to other behaviours such as substance abuse, dietary change, exercise promotion and safe sex. ${ }^{9}$ While none of these models is perfect for FGM/C, issues of individualism, self efficacy, negotiation and power/ influence are relevant. Combating FGM/C transcends the individual because individuals have to submit for scrutiny their perspectives based on experiences and influence in the social context of normality at family and community levels to effect a decision. ${ }^{6}$

The suggestion for a holistic approach to address all potential factors necessitated our effort to focus on adolescent girls who are potential future mothers and will have to make a decision whether to support the mutilation of their future daughters or otherwise. The study was aimed to determine the perception, experience and preparedness of adolescent girls to protect their future daughters from FGM/C.

\section{Methods}

The study was a cross-sectional survey conducted among female adolescent secondary school students aged 13 to 19 years in eighteen secondary schools in North Central Nigeria. Participating schools were selected via multistage sampling from the list of all secondary schools in the study area with provision for equal number of 
public and private schools. After information about the study, informed consent was obtained from those aged 18years and above while parental consent was obtained for younger participants. The sampling method was purposive sampling; thereafter, each participant completed a self-administered questionnaire for the study. The inclusion criteria were female gender, studentship in any of the study sites at the time of the study, age 13 to 19 years and consent (parental or from the participant). Those outside the age bracket for the study or without consent for participation were excluded from the study. The lower limit of age 13 years was chosen because those younger had difficulty in completing the questionnaire during its pre-test.

The sample size was calculated using the formula ${ }^{10}$

$\mathrm{n}=2 \mathrm{z}^{2} \mathrm{pq} / \mathrm{d}^{2}$

$\mathrm{n}=$ desired sample size

$\mathrm{z}=$ standard normal deviate set as 1.96 which corre-

sponds to $95 \%$ confidence interval

$\mathrm{p}=$ proportion in the target population estimated to

have FGM i.e. 0.253 (i.e. $25.3 \%$ ). ${ }^{3}$

$\mathrm{q}=1.0-0.253=0.747$

$\mathrm{d}=$ degree of accuracy desired set at 0.05

$$
\mathrm{n}=2 \times 1.96 \times 1.96 \times 0.253 \times 0.747=580.8
$$$$
(0.05)^{2}
$$

Thus, the minimum sample size was $581+116(20 \%$ for non-respondents) $=697$.
The information collected included demographic parameters, perception, attitude, experience about FG$\mathrm{M} / \mathrm{C}$ as well as the attitude towards its eradication. Participants' confidentiality was maintained by using codes instead of individual names. Statistical analysis was with SPSS version 20.0 (IBM, USA), the Pearson's chi square was used for comparison with calculation of odds ratio at $95 \%$ confidence interval while $P$-value $<0.05$ was termed significant.

Ethical approvals were obtained from the ethical review committee of the teaching hospital as well as the Kwara State Ministry of Education and Human Capital Development before the commencement of the study. Participation was voluntary and recruitment was after obtaining an informed consent for participation. The authors declare no conflict of interest in the conduct of the study.

\section{Results}

There were 2000 participants with mean age $15.56 \pm 1.75$ (range 13-19) years, 121(6.1\%) resided in rural area, $785(39.3 \%)$ were from low social class families, awareness about FGM/C was $86.1 \%, 1063(53.2 \%)$ have been aware for more than 4 years and the commonest source of information was the mother $(1018 ; 50.9 \%)$ as shown in table 1.

Table 1: Socio-demographic characteristics of the participants

\begin{tabular}{|c|c|c|}
\hline Socio-demographic variable & Frequency $(\mathrm{N}=\mathbf{2 0 0 0})$ & Percent \\
\hline \multicolumn{3}{|l|}{ Age } \\
\hline Range & $13-19$ & \\
\hline Mean age & $15.56 \pm 1.75$ & \\
\hline \multicolumn{3}{|l|}{ Residence } \\
\hline Rural & 121 & 6.1 \\
\hline Urban & 1879 & 94.0 \\
\hline \multicolumn{3}{|l|}{ School location } \\
\hline Rural & 157 & 7.9 \\
\hline Urban & 1843 & 92.2 \\
\hline \multicolumn{3}{|l|}{ Parents' social class } \\
\hline High & 1215 & 60.8 \\
\hline Low & 785 & 39.3 \\
\hline \multicolumn{3}{|l|}{ Awareness about FGM } \\
\hline Yes & 1721 & 86.1 \\
\hline No & 279 & 14.0 \\
\hline \multicolumn{3}{|c|}{ Duration of awareness about FGM/C (years) } \\
\hline$<2$ & 129 & 6.5 \\
\hline $2-4$ & 808 & 40.4 \\
\hline$>4$ & 1063 & 53.2 \\
\hline \multicolumn{3}{|l|}{ Source of information* } \\
\hline Poster & 29 & 1.5 \\
\hline Television & 126 & 6.3 \\
\hline Books & 135 & 6.8 \\
\hline Grandparents/ elders & 138 & 6.9 \\
\hline Radio & 150 & 7.5 \\
\hline Religious leaders & 169 & 8.5 \\
\hline Father & 389 & 19.5 \\
\hline Friends & 473 & 23.7 \\
\hline Teacher & 755 & 37.8 \\
\hline Mother & 1018 & 50.9 \\
\hline
\end{tabular}


Table 2 shows that the prevalence of FGM/C among participants was $35.0 \%$ while $21.1 \%$ were unsure if they had been mutilated. The mean age at mutilation was $3.85 \pm 3.24$ (range 1 to 8 ) years, 301(43.1\%) described the experience as paiful, 140(20.0\%) remembered that they bled excessively while $215(30.7 \%)$ could not remember the experience. Also, 669(33.5\%) were aware that traditional circumcisers performs FGM/C while $41.6 \%$ opined that healthcare workers $(28.3 \%$ for doc- tors and $13.3 \%$ for nurses) perform FGM/C. While $746(37.3 \%)$ opined that FGM/C has benefits, the common presumed benefits were control of sexual promiscuity $(29.2 \%)$ and making a female complete $(32.7 \%)$. In all, 958(47.9\%) had seen a victim of FGM/C previously, the common victims were siblings $(377 ; 39.3 \%)$, neighbor $(307 ; 32.0 \%)$ or relatives $(177(18.5)$ while $644(32.2 \%)$ reported the intention to circumcise their future daughters.

Table 2: Experiences and views about FGM/C among participants

\begin{tabular}{|c|c|c|}
\hline Variables & Frequency $(\mathrm{N}=\mathbf{2 0 0 0})$ & Percent \\
\hline \multicolumn{3}{|l|}{ I have been mutilated } \\
\hline Yes & 699 & 35.0 \\
\hline No & 877 & 43.9 \\
\hline I don't know & 424 & 21.1 \\
\hline Mean age at mutilation (years) & $3.85 \pm 3.24$ (range $1-8)$ & \\
\hline \multicolumn{3}{|c|}{ Description of mutilation experience $(n=699)$} \\
\hline Very painful & 301 & 43.1 \\
\hline Excessive bleeding & 140 & 20.0 \\
\hline I enjoyed it & 43 & 6.2 \\
\hline I cannot remember & 215 & 30.7 \\
\hline \multicolumn{3}{|c|}{ In my opinion, FGM/C is performed by } \\
\hline Religious leaders & 124 & 6.2 \\
\hline Nurse & 265 & 13.3 \\
\hline Older women in the community & 376 & 18.8 \\
\hline Doctor & 566 & 28.3 \\
\hline Traditional circumciser & 669 & 33.5 \\
\hline \multicolumn{3}{|l|}{ Think that FGM/C has benefits } \\
\hline Yes & 746 & 37.3 \\
\hline No & 1254 & 62.7 \\
\hline \multicolumn{3}{|l|}{ Presumed benefits of FGM/C $(n=746)$} \\
\hline Makes a woman complete & 244 & 32.7 \\
\hline Controls sexual promiscuity & 218 & 29.2 \\
\hline Removes bad part of female genitalia & 149 & 20.0 \\
\hline Makes childbearing easier & 135 & 18.1 \\
\hline \multicolumn{3}{|l|}{ Seen a victim of FGM/C before } \\
\hline Yes & 958 & 47.9 \\
\hline No & 1042 & 52.1 \\
\hline \multicolumn{3}{|c|}{ Description of the victim of FGM/C $(n=958)$} \\
\hline Playmate & 137 & 14.3 \\
\hline Relative & 177 & 18.4 \\
\hline Neighbor & 307 & 32.0 \\
\hline Sister & 377 & 39.3 \\
\hline \multicolumn{3}{|c|}{ I will subject my future daughter to $\mathrm{FGM} / \mathrm{C}$} \\
\hline Yes & 644 & 32.2 \\
\hline No & 1356 & 67.8 \\
\hline
\end{tabular}

Table 3 shows that awareness of efforts to eradicate FGM/C was $40.7 \%$ while the participants suggested community education and re-orientation (814; 40.7\%) and announcements in the media $(363 ; 18.2 \%)$. On see- ing a girl that is to be mutilated, $643(32.2 \%)$ of participants intended to plead with the parents to desist from the act, 558(27.9\%) intended to report to the police while $721(36.1 \%)$ described FGM/C as wickedness against women. 
Table 3: Attitude and response to eradication of FGM/C

\begin{tabular}{lll}
\hline Variables & $\begin{array}{l}\text { Frequency } \\
\text { (N= 2000) }\end{array}$ & Percent \\
\hline Aware of efforts to eradicate FGM/C & & \\
Yes & 813 & 40.7 \\
No & 1187 & 59.4 \\
Suggestion of activities to aid eradication of FGM/C & & \\
$\quad$ Community education/ re-orientation & 814 & 40.7 \\
Announcement on radio/television & 363 & 18.2 \\
Appeal to parents/adults & 304 & 15.2 \\
Arrest those assist in FGM/C & 206 & 10.2 \\
Punitive legislation against parents of the victims & 313 & 15.7 \\
Possible response on seeing a girl about to be mutilated & & \\
Carry and hide the child & 86 & 4.3 \\
Take child to religious home & 106 & 5.3 \\
Stay and watch how it is performed & 255 & 12.8 \\
Take the child to the hospital & 352 & 17.6 \\
Report to the police & 558 & 27.9 \\
Beg the parents not to do it & 643 & 32.2 \\
Description of FGM/C & & \\
Good for girls & 355 & 17.8 \\
Makes a girl to become a real woman & 430 & 21.5 \\
It is old-fashioned & 494 & 24.7 \\
Wickedness against women & 721 & 36.1 \\
\hline
\end{tabular}

Table 4 shows that majority of participants who were positively predisposed to FGM/C were from low social class families (P 0.001), resides in urban area (P0.001) and had seen a victim of FGM/C previously (P0.001). However, $16.8 \%$ of those who perceived FGM/C as wickedness against females and $38.0 \%$ of those thought it makes the women a real women planned to circumcise their children. Furthermore, significant number of girls who intended to mutilate future daughters supported the call to continue FGM/C (P0.001).

Table 5 shows that the determinants of support for continuation of FGM/C were being a victim (OR0.191, 95\% CI O.141-0.257; P0.001) or having the opinion that FGM/C is beneficial (OR0.108, 95\%CI 0.080-0.145; P0.001) while seeing a victim of FGM/C (OR0.387, 95\%CI 0.288-0.519; P0.001) encourages support for its eradication. 
Table 4: Associated factors related to attitude concerning FGM/C

\begin{tabular}{|c|c|c|c|c|c|}
\hline \multirow{2}{*}{ Variable } & \multicolumn{3}{|c|}{ Should girls be circumcised } & \multirow[t]{2}{*}{$\chi^{2}$} & \multirow[t]{2}{*}{ P-value } \\
\hline & $\begin{array}{l}\text { Yes } \\
\text { n (\%) }\end{array}$ & $\begin{array}{l}\text { No } \\
\text { n (\%) }\end{array}$ & $\begin{array}{l}\text { I don't know } \\
\text { n (\%) }\end{array}$ & & \\
\hline \multicolumn{6}{|l|}{ Social class } \\
\hline High & $354(49.0)$ & $601(73.4)$ & $199(43.4)$ & 213.72 & 0.001 \\
\hline Low & $368(51.0)$ & $218(26.6)$ & $260(56.6)$ & 42.46 & 0.001 \\
\hline \multicolumn{6}{|l|}{ Residence } \\
\hline Rural & $33(4.6)$ & $56(6.8)$ & $32(7.0)$ & 9.14 & 0.010 \\
\hline Urban & $689(95.4)$ & $763(93.2)$ & $427(93.0)$ & 99.53 & 0.001 \\
\hline \multicolumn{6}{|l|}{ School location } \\
\hline Rural & $64(8.9)$ & $59(7.2)$ & $34(7.4)$ & 9.87 & 0.007 \\
\hline Urban & $658(91.1)$ & $760(92.8)$ & $425(92.6)$ & 95.99 & 0.001 \\
\hline \multicolumn{6}{|l|}{ Seen victim of FGM/C before } \\
\hline Yes & $533(73.8)$ & $254(31.0)$ & $171(37.3)$ & 225.23 & 0.001 \\
\hline No & $189(26.2)$ & $565(69.0)$ & $288(62.7)$ & 218.72 & 0.001 \\
\hline \multicolumn{6}{|l|}{ Description of FGM/C? } \\
\hline Wickedness against females & $121(16.8)$ & $477(58.2)$ & $123(26.8)$ & 349.59 & 0.001 \\
\hline Old fashioned & $110(15.2)$ & $248(30.3)$ & $136(29.6)$ & 65.31 & 0.001 \\
\hline Good for girls & $217(30.1)$ & $50(6.1)$ & $88(19.2)$ & 129.50 & 0.001 \\
\hline Makes someone a real woman & $274(38.0)$ & $44(5.4)$ & $112(24.4)$ & 194.80 & 0.001 \\
\hline \multicolumn{6}{|l|}{ FGM/C has benefits to girls } \\
\hline Yes & $493(68.3)$ & $103(12.6)$ & $150(32.7)$ & 364.55 & 0.001 \\
\hline No & $229(31.7)$ & $716(87.4)$ & $309(67.3)$ & 326.33 & 0.001 \\
\hline \multicolumn{6}{|l|}{ Will mutilate future daughter } \\
\hline Yes & $447(61.9)$ & $88(10.7)$ & $109(23.7)$ & 378.20 & 0.001 \\
\hline No & $275(38.1)$ & $731(89.3)$ & $350(76.3)$ & 264.54 & 0.001 \\
\hline \multicolumn{6}{|l|}{$\begin{array}{l}\text { Aware of effort to } \\
\text { eradicate FGM/C }\end{array}$} \\
\hline Yes & $222(30.7)$ & $433(52.9)$ & $158(34.4)$ & 152.81 & 0.001 \\
\hline No & $500(69.3)$ & $386(47.1)$ & $301(65.6)$ & 50.39 & 0.001 \\
\hline
\end{tabular}

Table 5: Determinants of support to FGM/C among participants

\begin{tabular}{lllll}
\hline Variable & $\begin{array}{l}\text { P- } \\
\text { value }\end{array}$ & OR & 95\% CI for OR \\
& & & Lower & Upper \\
\hline Awareness about FGM/C & 0.517 & 0.858 & 0.540 & 1.363 \\
Correct definition of FGM/C & 0.636 & 0.928 & 0.680 & 1.266 \\
A victim of FGM/C & 0.001 & 0.191 & 0.141 & 0.257 \\
Have seen a victim of FGM/C before & 0.001 & 0.387 & 0.288 & 0.519 \\
Opinion that FGM/C is beneficial to females & 0.001 & 0.108 & 0.080 & 0.145 \\
\hline
\end{tabular}

\section{Discussion}

The prevalence of FGM/C among adolescent girls in the study was $35.0 \%$; participants were mutilated at infancy to early childhood and about half could still recollect the trauma associated with the mutilation. A third of participants opined that FGM/C has some presumed benefits; therefore they expressed support for the act and intend to circumcise their future daughters. Also, about a third recalled having siblings who were victims of FGMC while less than half were aware of efforts aimed at its eradication. Determinants of support for eradication of FGM/C were awareness of efforts aimed at its eradication and participants who had seen a victim of FGM/C previously while those who presumed that FGM/C has some benefits or expressed desire to circumcise future daughters supported its continuation.

The prevalence of $\mathrm{FGM} / \mathrm{C}$ in this study is higher than the national prevalence of 1 in 4 reported in the $\mathrm{Na}$ tional Demographic Health Survey (NDHS) ${ }^{11}$ and 
$25.3 \%$ from the MICS in Nigeria. ${ }^{3}$ Compared to the MICS report, the $35.0 \%$ reported in this study is higher than the regional prevalence of $16.1 \%$ for north-central but comparable to the $40.6 \%$ reported for the state where the study was conducted. ${ }^{3}$ This suggests that the sample size in the study was representative of the situation in the state (locality); therefore, local reports may differ from national prevalence which is an aggregate value. However, the prevalence in this study is higher than 1.4\% in Ghana and 14.6\% in Kenya but lower than $80.7 \%$ in Egypt and $96.7 \%$ in Somalia. ${ }^{12}$ In a report from Ethiopia, the prevalence of FGM/C was $96 \%$ among adult women, 49\% among their daughters less than 5 years and $91 \%$ in children less than one year. ${ }^{13}$ The differences may be a reflection of the variations in prevalence of FGM/C among countries.

FGM/C was performed before the eighth birthday in this study, this compares to reports of infancy from south-east Nigeria ${ }^{14}$ or age two years or less in Ethiopia $;^{13}$ generally, mutilation was reported to be performed before age five in almost half of countries practicing it. ${ }^{15} \mathrm{FGM} / \mathrm{C}$ is performed mostly by local circumcisers as affirmed by majority (33.5\%) of participants in this study; these are lay men and women who mutilate girls while the victims are physically restrained. ${ }^{12}$ This is associated with pain, apprehension and blood loss such that about two-thirds of participants in this study were able to recall such negative experiences of severe pain and bleeding after about a decade post-mutilation. Researchers have highlighted the impact of negative early life experiences on the health of individuals, such adverse childhood experiences (ACE) could be direct (abuse and neglect) similar to FGM/C or indirect through the living environments (parental conflict, substance abuse, mental illness). ${ }^{17}$ Reports indicated an association between ACEs and increased risk of poor health outcomes, drug addiction, interpersonal and self-directed violence $^{17}$ as well as a consistent negative set of adult life outcomes. ${ }^{18}$ Although these were not evaluated in this study, efforts should be directed towards effective and widely available preventive interventions to counter these probable negative long-term sequelae of FGM/C as a form of ACE.

The high level of awareness about FGM/C in this study compares to $42.6 \%{ }^{19}$ and $79.3 \%{ }^{20}$ reported from studies in Nigeria; however, this has not changed the attitude to the act significantly. FGM/C has no health benefit; it causes physical and mental harm and is a human right abuse and breach of the basic right of girls and women by invading their healthy body tissue. Reported medical sequelae included labial adhesion and clitoral cyst, ${ }^{21}$ dysmenorrhea, obstructed labour and postpartum haemorrhage, ${ }^{22}$ wound infection, recurrent UTI,15 significantly higher risk for episiotomy, perineal tear, caesarean delivery and neonatal complications including stillbirth. ${ }^{14}$ Psychological sequelae and impaired sexual function can occur with all types of FGM/C,15 these may include loss of sexual desire, inadequate genital lubrication during coitus, inability to achieve orgasm and sexual dissatisfaction. ${ }^{22}$

However, despite the problems associated with FG$\mathrm{M} / \mathrm{C}$, the act persists; in a report from Nigeria, 33.3\% of the victims expressed support for the act. ${ }^{21} \mathrm{~A}$ systematic review identified the factors favoring the perpetuation of FGM/C as an interplay of culture, tradition, sexual morals, marriageability, religion, presumed health benefits and male sexual enjoyment. ${ }^{23}$ In Nigeria, culture $(60.8 \%),{ }^{14}$ tradition $(34.4 \%)$ and better marriage prospect $(21.5 \%)^{20}$ have been identified as factors favouring continuation of FGM/C while this study identified the perception that FGM/C makes a woman complete, control of female sexuality and easier childbirth. Some culture regard FGM/C as a form of female gender identity aimed at preservation of family honour; therefore, many girls are forced to conform to avoid being teased or ostracised. ${ }^{24}$ The economic dimension of FGM/C encourages stitching of the introitus to guarantee virginity as a way to attract huge bride price in poor communities where the female child is considered a source of family income ${ }^{24}$ although this was not evaluated in this study.

In this study, $21 \%$ of respondents were unsure whether they have experienced FGM/C or not. Possible explanations for this include denial by mutilated individuals, lack of awareness due to less severe forms of FGM/C with minimal symptoms (type I), mutilation at very young age with failure of recall while some participants may not have been mutilated. ${ }^{25}$ This is an important limitation of studies based on self-reporting of FGM/C because confirmation by physical examination portends ethical challenges. In addition, certain discrepancies were noticed in the result of this study. This includes the observation that some participants who favoured continuation of $\mathrm{FGM} / \mathrm{C}$ perceived the act as wickedness against women or indicated their unwillingness to circumcise their daughters. This underscores the dynamics of the non-linear relationship between information, intention and behavioural change. 
According to the trans-theoretical model, such individuals are reluctant abandoners because they have a high probability to abandon FGM/C despite their favour for its continuation provided other decision-makers or social pressure indicate otherwise. ${ }^{9}$ This group can be targeted for positive influence by ambassadors of FG$\mathrm{M} / \mathrm{C}$ to discontinue the act. In addition, women who did not favour continuation of FGM/C and will not mutilate their daughters are called willing abandoners while those who supported the continuation of the act and plan to mutilate their daughters are termed willing adherents. ${ }^{9}$ Conversely, some women who supported the eradication of FGM/C may not act out their belief if the social context encourages reward for adherence or sanctions for non-conformance ${ }^{25}$, while $52.6 \%$ of mutilated women comprising mothers and grandmas insisted on female mutilation. ${ }^{22}$ A report among pregnant women in a rural north-west area in Nigeria indicated that $21.5 \%$ intended to mutilate the unborn children if they turned out to be daughters after delivery. ${ }^{20}$ In another study among school teachers, male teachers were the major initiator of their daughters' mutilation while grandmothers were the significant female proponent for FGM/C. ${ }^{27}$ Circumcisers derive remunerations from performing FGM/C while some depend solely on it for their livelihood. Therefore, they represent another important group of stakeholders who may encourage the continuation of the act. ${ }^{16}$

Moving forward in the effort to eradicate FGM/C, the multi-pronged approach remains relevant. The social and economic dimensions should be addressed because FGM/C is rooted in tradition and cultural beliefs which define the social values of any community. The communal force is such that members with dissenting opinion are forced to comply with the social norm to avoid embarrassment. In instances where dissenting members have acted out their disapproval, it has been met with significant communal outcry and reprimand. Therefore, since FGM/C thrives on the communal belief system, community re-orientation, education and innovation with alternative healthy ceremonies for initiation of young girls into adulthood has been suggested. ${ }^{24}$ In some communities, the birth of a female child is regarded as an investment which yield dividend as huge bride price. This is based on virginity at marriage prompting the use of $\mathrm{FGM} / \mathrm{C}$ as a deterrent to premarital sex. Therefore, economic empowerment for the families in such areas should receive attention while the classification of FGM/C as a reportable health condition will be desirable. Furthermore, the inclusion of
FGM/C and other gender-based violence in the school curriculum as a mode of dissemination of correct information to the students will improve their resilience to eradicate the act.

This study concludes that FGM/C remains prevalent with a probability that the female adolescent participants may support its continuation unless efforts at its eradication are prioritized. Also, FGM/C is a significant adverse childhood experience whose negative landmarks remained with its victims and portends a probable source of adolescent and adult psychological problems. The multi-pronged approach to eradicate FGM/C should prioritize re-orientation of adolescent girls, rehabilitation of mutilated girls and universal girl child formal education to equip the girls as advocates of the eradication of $\mathrm{FGM} / \mathrm{C}$.

\section{References}

1. WHO. Global strategy to stop health-care providers from performing female genital mutilation UNAIDS, UNDP, UNFPA, UNICEF, UNHCR, UNIFEM, WHO, FIGO, ICN, IOM, WCPT, WMA, MWIA. Geneva; WHO Press 2010.

2. UNFPA. Projections of number of young girls ages 15-19 who will experience FM/C from 2010-2030. Technical Division, UNFPA, September 2013.

3. National Bureau of Statistics and United Nations Children's Fund. Multiple Indicator Cluster Survey 2016-17 Survey Findings Report. 2017. Abuja: National Bureau of Statistics and United Nations Children's Fund.

4. WHO. Eliminating female genital mutilation. An interagency statement- OHCHR, UNAIDS, UNDP, UNECA, UNESCO, UNFPA, UNHCR, UNICEF, UNIFEM, WHO. 20O8. Available at: www.who.int/reproductive-health. Accessed on 25/4/2019.

5. Frontiers in Reproductive Health/ Population Council. Using operations research to strengthen programmes for encouraging abandonment of female genital cutting. (Report of a consultative meeting on methodological issues for FGC Research, April 9-11, 2002, Nairobi, Kenya, 2002).

6. Shell-Duncan B, Herniund Y. Are there 'stages of change' in the practice of female genital cutting?: Qualitative research findings from Senegal and the Gambia. Afr J Reprod Health 2006;10(2):57-71.

7. Rogers E. Diffusion of innovation. New York, The Free Press, 1995.

8. Prochasca JO, DiClemente CC. In search of how people change: Application of addictive behaviours. Am Psychologist 1992;47:1102-1114. 
9. Prochasca JO, Velicer WF, Rossi JS, Goldstein MG, Marcus BH, Rakowski W, et al. Stage of change and decisional balance for 12 problem behaviours. Health Psychology 1994;13:39-46.

10. Araoye MO. Research Methodology with Statistics for Health and Social sciences. Ilorin: Nathadex Press, 2003.

11. National Population Commission (NPC), Nigeria and ICF international. Nigeria Demographic and Health Survey 2013. Abuja, Nigeria and Maryland USA: NPC and ICF international, 2014.p. 345-358.

12. Population Reference Bureau. Female genital mutilation: Data and Trends 2010. Washington DC; PRB, 2010.

13. Andualem M. Determinants of female genital mutilation practices in East Gojjam zone, Western Amhara, Ethiopia. Ethiop Med J 2016;54(3):109-116.

14. Lawani LO, Onyebuchi AK, Iyoke CA, Okeke

NE. Female genital mutilation and efforts to achieve Millennium Development Goals 3,4 and 5 in Southeast Nigeria. Int J Gynae Obstet 2014;125:125-128.

15. RCOG. Female Genital Mutilation and its management. Green-top guideline No. 53, July 2015.

16. Adeniran AS, Ijaiya MA, Adesina KT, Balogun OR, Uthman MM, Salaudeen AG, et al. Exploring the practice and attitude of circumcisers in the eradication of female genital mutilation/ cutting. J Obstet Gynaecol East Central Afr 2016;28(1):7-11.

17. Hughes K, Bellis MA, Hardcastle KA, Sethi D, Butchart A, Mikton C, et al. The effect of multiple adverse childhood experiences on health: a systematic review and meta-analysis. Lancet Pub Health 2017;2:e35666.

18. Giovanelli A, Reynolds AJ, Mondi CF, Ou S. Adverse childhood experiences and adult well-being in a low income urban cohort. Paediatrics 2016;137(4):e20154016. doi: 10.1542/peds.2015-4016.
19. Abiodun AA, Oyejola BA, Obalowu J. Female circumcision in Nigeria, Prevalence and Attitudes. Centrepoint 2011;17(2):89-98.

20. Ashimi AO, Amole TG. Perception and attitude of pregnant women in a rural community north-west Nigeria to female genital mutilation. Arch Gynecol Obstet 2015;291(3):695-700.

21. Adeniran AS, Aboyeji AP, Ijaiya MA, Balogun OR. Eradicating Female Genital Mutilation: Case Series Evaluating the Effect of Interventions. University Mauritius Res J 2014;20(1):1-8.

22. Mahmoud MIH. Effect of female genital mutilation on female sexual dysfunction, Alexandria, Egypt. Alexandria J Med 2016;52:55-59.

23. Berg RC, Denison E. A tradition in Transition: Factors perpetuating and hindering the continuance of female genital mutilation/cutting (FM/C) summarized in a systematic review. Health Care Women Int 2013;34:837-859.

24. Althaus FA. Female circumcision: Rite of passage or violation of rights? Int Fam Plann Perspectives 1997;23(3):130-133.

25. UNICEF. Female genital mutilation/cutting: A statistical overview and exploration of the dynamics of change. 2013. New York, UNICEF. Available at: www. childinfo.org

26. Adeniran AS, Ijaiya MA, Fawole AA, Balogun OR, Adesina KT, Olatinwo AWO, et al. Attitudes to female genital mutilation/ cutting among male adolescents in Ilorin, Nigeria. South Afr Med J 2016;106(8):822823.

27. Adeniran AS, Fawole AA, Balogun OR, Ijaiya MA, Adesina KT, Adeniran IP. Female genital mutilation/cutting: Knowledge, Practice and experiences of secondary school teachers in North Central Nigeria. South Afr J Obstet Gynaecol 2015;21(2):39-43. 